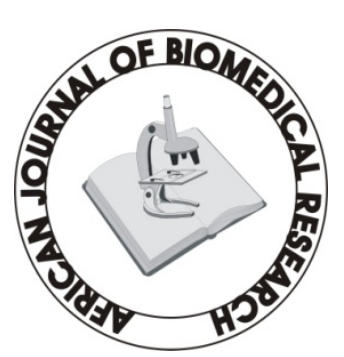

Full-text available at http://www.ajbrui.com http://www.bioline.br/md http://www.ajol.com

Received:

May 2007

Accepted (Revised): November 2007

Published January 2008
Review Article

\section{Environmental Chemicals and Human Neurotoxicity: Magnitude, Prognosis and Markers}

\author{
Anetor J. I. ${ }^{1}$, Anetor G.O. ${ }^{2}$, Iyanda AA ${ }^{1}$, Adeniyi FAA ${ }^{1}$ \\ Departments of ${ }^{1}$ Chemical Pathology and ${ }^{2}$ Human Kinetics/ Health Education \\ University of Ibadan, Ibadan, Nigeria
}

\section{ABSTRACT}

The neurotoxic effects of exposure to chemicals in the environment, though insufficiently recognized, remains a topic of substantial current concern and interest. Neurotoxicities may be protean; expressed as neuropathologic or as altered neurocthemical, electrophysiological or behavioural functions. The adverse effects of neurotoxicity are among the most feared ill health in humans because they adversely affect the quality of life, and have broad health, social and economic implications. Though the magnitude of neurotoxicity is not exactly known, in some advanced countries over 30 million individuals suffer from neurobehavioural illness with only $20 \%$ seeking medical attention. In the United States for instance, of the 63 million youths under 18 years of age about 10\% have diagnosable neurobehavioural problems with only 20\% receiving therapy. Data developed by the massive Global Burden of Disease (GBD) revealed that neurobehavioural impairment ranks only second to cancer and coronary heart disease combined. These data may indeed be more gruesome owing to the poor regulation of exposure to environmental chemicals in resource poor countries. Biomarkers play a major role in detecting, predicting and screening for neurotoxicity. Development of inexpensive and specific biomarkers of neurotoxicity is a challenge to the scientific community. Undoubtedly, the magnitude and potential severity of neurotoxicity problems make it imperative to invest in resources required to strengthen the basis for preventive intervention, the forerunner of which is the development of biomarkers for neurotoxicity at the individual and population levels. Health education on chemicals and potential for neurotoxicity is also desirable.

(Afr. J. Biomed. Res. 11: 1 -12)

Key Words; Environmental Chemicals, Neurotoxicity, Markers, Micronutrients, Pollution.

*Address for Correspondence: anetorji@yahoo.com

Abstracted by:

African Index Medicus (WHO), CAB Abstracts, Index Copernicus, Global Health Abstracts, Asian Science Index, Index

Veterinarius, Bioline International , African Journals online 


\section{INTRODUCTION}

Nearly six decades ago, about the period the World Health Organization (WHO) was being formed, concern about chemical safety already existed. At the time, the magnitude of production of individual chemicals and range of molecules differed from the situation today.

Chemicals now account for about $10 \%$ of total world trade in terms of value (about US\$ 1500 billion) some 70,00 to 80,000 chemicals are on the commercial market and hence in the environment. Every year 1000 - 2000 new chemicals enter the market and consequently the environment (Kreisel, 1998). Neurotoxic chemicals are significant contributors to human health problems that result from environmental and work place chemical exposure (Donkin and Williams, 2000).

The National Institute for Occupational Safety and Health (NIOSH) reports that exposure to neurotoxic chemicals is one of the 10 leading causes of work-related disease and injury and that over $25 \%$ of the chemicals for which the American Conference of Governmental Industrial Hygienists (ACGIH) has established threshold limit values (TLV) have demonstrated nervous system effects. Other investigators have estimated that of the 400 or so commonly used chemicals (primarily solvents) and the various pesticides, $42 \%$ are neurotoxic (Donkin \& Williams 2000). Thus neurotoxicity is an important consequence of human exposure to industrial chemicals. But this is very poorly recognized particular in countries producing a lot of petrochemicals. Beside being work place hazards, many neurotoxicants find their way into the environment through either deliberate or inadvertent release. Thus the general population may become exposed to these chemicals through air, food, or drinking water.

The infamous Minamata bay incident of the 1950s, in which residents of a coastal Japanese town suffered severe and occasionally fatal neurotoxicity from methyl mercury poisoning is only one example. In this case, exposure was due to ingestion of fish contaminated by discharge from local acetaldehyde plant.

As humans are exposed to a variety of environmental chemicals, identifying a specific toxic agent causing a particular toxic effect is often difficult.

Environmental exposure levels are usually, except in extreme cases, not so high as to cause clearcut symptoms in all individuals. More often, the situation is such that only a subset of an exposed population (cohort) (presumably those that are most highly exposed or sensitive) show symptoms of varying degrees.

Neurotoxic effects often appear as changes in behaviour that may serve as early warning signs of further toxicity possibly occurring if exposure is continued. For instance neurotoxic effects may be found among individuals exposed to dissolved metals such as lead and arsenic in drinking water.

This article presents a concise review of neurotoxicity and the unrecognized problem populations in this environment may face. The need for better biomarkers of susceptibility, improved risk assessment, clinical evaluation and preventive measures for susceptible populations is highlighted.

\section{The International Programme On Chemical Safety (IPCS)}

The IPCS was established specifically as a response to the environmental and health challenges of chemicals to produce assessments of the risk of chemicals to human health and the environment; providing the scientific basis on which member states could develop their own chemical measures. An impressive list of commonly used and internationally traded agricultural and industrial chemicals has been evaluated since its inception (IPCS, 1992). How well these functions are carried out locally in this sub-region remains a question for great speculation.

\section{Chemical Toxicity}

One of the most serious consequences of the huge and continually expanding world market in chemicals is the ready availability to the general public of large numbers of very hazardous substances. Children are at particular risk of chemical toxicity. In chemical risk assessment, cancer studies predominate, obviously because it is a dramatic disease, often with tragic consequences at a personal level. However, it is 
important to note that it is becoming increasingly evident that investigations into the subtle effects of chemicals (especially bioaccumulable ones) at very low concentrations on the unborn child need to be extended to such other areas as neurotoxicity and endocrine disruptions. The list of endocrine disruptions caused by endocrine active chemicals (EACs) or endocrine disrupting chemicals (EDCs) is on the increase and the public fear that problems such as the fall in human sperm count (Carlsen et al, 1992) could ultimately have grave consequences for the human species need to be taken seriously in this part of the world - data are unavailable generally from the developing countries.

The reduction in the number of occupational cancers in industrialized countries is in part attributed to the transfer of hazardous industries to developing countries (Huff and Tomatis, 2001).

Recent reports also indicate that occupational cancers are now becoming serious problems in developing countries where industrialization is a rather recent phenomenon and where exposure levels to hazardous chemicals considerably exceed regulatory levels established in the industrialized countries (Poarco, Matos, Vainio, Bolletha, Kongevinas, 1994; Castleman, 1999).

\section{Human Neurotoxicity}

Though cancer has been the main concern about chemicals, the neuro-behavioural effects of exposure to chemicals remains a topic of substantial current concern and interest (Walker, 2000, Carpenter, 2002). These concerns are evident in public health systems, among toxicologists, veteran organizations and industrial and agricultural watch dog groups as well as many other health, medical, environmental and advocacy groups. The growing list of neurotoxicities induced mainly by synthetic chemicals is yet to experience a decline. These neurotoxicities may be expressed as neuropathologic or as altered neurochemical, electrophysiologic or behavioural functions for example organophosphate compounds which inhibit acetylchlinesterase leading to build up of acetylcholine at the acetylcholine receptor synayse, carbondisulphide which inhibits dopamine $\beta$-hydroxylase,
Manganese which inhibits dopamine formation by inhibiting tyrosine hydroxylase in the striatum (Bonilla, 1980). These adverse effects are among the most feared ill health in human beings because they very adversely affect the quality of life. Currently an expending base of consistent findings affirms that neurobahavioural toxicity is a significant outcome of exposure to environmental chemicals (Walker, 2000).

The expressions of neurotoxic response can be progressive, with small function deficits becoming more serious. At this point it is difficult to define the onset of neurologic impairment. A small change in neurologic function could serve as a marker of exposure to a neurotoxicant, a moderate biologic alterations might well signal or point to neurologic disease and a large alteration may indicate advanced disorder.

\section{The Magnitude of The Problem}

It is unfortunate that in a disorder of such significance the precise number of subjects with neurologic disorders involved is not known. However, very few would question the apparent upsurge in the incidence and prevalence of neurobehavioural disease as indicated by best available data. Data are unavailable in this part of the world. But data from the United States may serve to illustrate the magnitude of the problem. In any given year estimates are that 30 million Americans suffer from neurobehavioural illness, but only $20 \%$ seek medical help. Of the nation's 63 million people under 18 years of age 7.5 million

(> 10\%) have diagnosable neurobehavioural problems, but only about a fifth now receive treatment (Walker, 2000).

Data developed by the Massive Global Burden of Disease (GBD) study showed that neurobehavioural impairment ranks second only to the burden of disease established in market economies such as the United States, that is cancer and heart disease.

The first comprehensive census of the rapidly growing number of individuals with neurobehavioural disorders in American prisons found 283,800 inmates with mental illness, about $16 \%$ of the prison population. Taken as a group, 
neurobehavioural illnesses not only have social consequences but also impose significant financial and personal costs to people who experience them, to their communities and most seriously, to the national public health. These health problems cost nations that pay attention to all aspects of health such as the United States about \$ 150 billion annually. This includes cost of direct treatment, lost productivity, criminal justice costs, and property losses. It is the belief of many observers that the health and economic costs of neurobehavioural disorders may well exceed those of more widely discussed diseases such as cancer and cardiovascular disorders.

In the past, epidemics of neuotoxic disease related directly to environmental exposure having occurred including, ataxia caused by organic mercury in fish from Minamata Bay, Japan, (Tsubaki and Trukayama, 1977) and fungicidetreated grain in Iraq. These epidemics affected thousands of people. An important question, infact, a central issue challenging neurotoxicology today - is whether the causal associations observed in these earlier epidemics are reflections of isolated events or they were merely the most obvious and dramatic illustrations of a widespread association between environmental chemicals and nervous system toxicity. The question though not frequently asked in this country is a relevant one in view of the progressive industrialization and urbanization with attendant neurotoxicity. The restive Niger Delta Youths; could the substantial chemical pollution of the environment contribute to their neurobehavioural conditions ? 2, 5 hexanedione (2,5-HD) a metabolite of aliphatic hydrocarbons has been implicated in neurotoxicity Or could environmental chemicals contribute to the rising level of crime in our society?

\section{Global Chemical Trade Picture}

The magnitude of exposure to environmental neurotoxicants is greater than most individuals realize. It is estimated that over 80,000 chemicals are in use in some of the most developed countries like the United States and that an average of about 2000 new ones are introduced annually (Kreisel 1998, Carpenter et al, 2002). The Toxic Substance Control Act inventory of the United States contains over 70,000 chemicals and more than 3000 are added to the inventory annually. The United States Environmental Protection Agency's (EPA's) Toxic Release Inventory is useful but is an insufficiently comprehensive estimate of toxic releases into the environment. It reports that in 1996 22,000 facilities released 2.26 billion pounds of toxic chemicals into the environment. In the same year a single plant released nearly 50 tons a day of carbon disulphide, a well recognized neurotoxicant (USEPA, 1996). Similar data from FEPA (now Ministry of the Environment) are unavailable in Nigeria. But the Koko episode is still fresh in our minds. It has been reported that one fourth (25\%) of all chemicals frequently encountered in the environment may be neurotoxic (Congress of the United States, 1990). A more recent assessment of exposure to environmental chemicals indicates that even the most basic toxicity test (Markers) could not be found any where in the available public records for about $75 \%$ of the top volume chemicals in commercial use in countries as technologically advanced as the United States (Johnson, 1997). The National Academy of Sciences (NAS) of the United State has observed that there are readily available approaches to detect and identify behavioural deficits but that neurotoxicity data on many chemicals which are in turn dependent on markers are lacking. This has resulted in a limitation that constrains efforts to assess risks based on observed behavioural effects in humans. Restating this, it means that an increasing number of potential environmental neurotoxicants to which humans are exposed await the development of markers. This is an urgent challenge to environmental biochemists/toxicologists particularly in developing countries. Health education is also a veritable weapon against chemical toxicity but is often underrated because the problem is insidious. Seriously health education experts should consider chemical toxicity an area of concern before the problem explodes and becomes uncontrollable.

\section{Lead: A Pervasive Prime example of Neurotoxicants}

Over the last three decades, lead $(\mathrm{Pb})$ has been intensively studied. A lot more is known about the 
neuro-behavioural toxicity of this metal than any other environmental chemical. In fact the recognition of lead as a neurotoxicant was discovered initially in the ancient world where classic signs of lead poisoning such as palour and palsy were recognized. At that time, it was believed that neurorotoxic effects would not develop in human beings after exposure to low concentrations in the non-occupational or community settings.

Regardless of the gradual disappearance of lead compounds such as lead-based paints from common use, lead exposure from environmental and occupational sources still remains of great concern particularly in developing counties (Anetor, 2001). Indeed, Africa's contribution to global lead pollution has risen from about $5 \%$ in early 1980 s to about $20 \%$ a decade later (Nriagu et al, 1992). Until recently (Situation not quite clear). Nigeria had one of the highest lead content of gasoline consumed in the world (Thoms et al, 1999), combustions of which releases a lot of $\mathrm{Pb}$ into the environment. It is now well known that inorganic and organic lead compounds have neurotoxic effects on central and peripheral nervous systems in humans and animals especially in infancy (Shellenperger, 1984). Pabello and Bolivar (2005) have very recently commented on adult neurological consequences of lead exposure.

Heavy metal compounds and pesticides that have an adverse effect on the structure and function of the central and or/peripheral nervous system may be among the most common environmental pollutants that cause neurotoxicity. The neurotoxic effects of these chemicals will occur when their target sites within the nervous system are exposed to a sufficient dose of the compounds or their active metabolites for a length of time that is sufficient to induce biological changes.

Exposure may culminate in biochemical, physiological, morphological, functional, biophysical, pharmacological or behavioural changes which may be observed as the signs and symptoms of neurotoxicity (Kobayashi et al, 1994).

Abundant evidence exists of the pervasiveness of lead. The 1979, landmark study of Needleman and his colleagues found that environmental sources of lead can produce intellectual (i.e., decreased IQ) impairments in children at levels that may be considered of low risk significance (Needleman et al, 1979). Of recent there have been numerous indications that more research to elucidate the mode of action of lead is needed. Insights into the mechanisms of neuralogic effects on the developing brain have come from clinical and experimental studies. These investigations have revealed the mechanisms involved to be both morphologic and Pharmacological. In lead toxicity a morphologic effect is the result of $\mathrm{Pb}$ impairment of the timed programming (or regulated) cell-tocell connections, which guide the generation of circuitry during brain development mostly prenatal. This impairment results in modification of neural "net work" or circuitry (Szpin, 2006). The ensuing, disruption of the matching process of neural connections - or "mis-wiring" - may induce functional deficits (Brell et al, 1982).

Pharmacologically, $\mathrm{Pb}$ interferers with the process of neurotransmission from one cell to another at a synapse. Lead does this by blocking conductanse through neuronal calcium and $\mathrm{K}^{+}$ channels as well as responses to activation of accetylcholine, andrenergic, angiotensin and glutamate receptors. Though these responses occur at doses greater than those that are common for most humans (Silbergeld, 1992, Verity et al 1995) in our highly polluted environment (Okoye, 1994, Adeniyi and Anetor 1999, Anetor and Adeniyi, 2000), this may be the rule rather than the exception. Studies have demonstrated two mechanism by which low concentrations of $\mathrm{Pb}$ adversely influence the integrity of the blood-brain (BB) barrier viz: - the potentiation of lipo polysaccharide or interleukin-6-(IL - 6)-induced increase in ion permeability of the blood-brain barrier and secondly the glutamate-induced increase in permeability of the BB barrier. Several other lines of evidence implicate disturbances in the doparminergic (and glutaminergic neurotransmitter system) in the neurobehavioural expression of $\mathrm{Pb}$ toxicity (Kobayashi et al, 1994) 


\section{Emerging Data on Lead and Declining Level of Toxic Dose}

With each passing decade, public health officials have revised the definition of lead poisoning. Before the 1960s, a blood lead level (BLL) of $60 \mathrm{ug} / \mathrm{dL}$, was considered poisonous (toxic). In the late 1970s, lead was defined toxic at levels of 30ug/dL. In1991, the Centers for Disease Control and Prevention (CDC) after reviewing the clinical data, defined levels as low as $10 \mathrm{ug} / \mathrm{dL}$ as hazardous for growing children. More recent studies have suggested even lower levels as poisonous. It is interesting to note that an estimated BLL of well over two-fold what the CDC proposed in (1991) exists in our subregion (Anetor, 2001). Indeed Nriagu et al (1996) said that over $90 \%$ of children in Africa suffer from $\mathrm{Pb}$ toxicity.

As the scope of research on lead continues to expand globally, it has become clear that there is an overall decline in most developed countries of BLL (true situation in Nigeria remains uncertain) since the 1970s. This is a desirable trend and is consistent with the 20-year goal of the United States CDC for the elimination of childhood lead poisoning.

Paradoxically, a large number of children continue to have elevated lead levels ( $>10 \mathrm{ug} / \mathrm{dL}$ ) particularly in Africa and other developing countries and are at risk of neurobehavioral toxicity. Recent estimates put the number at 0.9 Million $(890,000)$ preschool children in the United States (Ryan et al, 1999). A conservative estimates puts it as $90 \%$ of all children in Africa (Nriagu, 1996). The neurotoxic implications is glaring.

Relatedly, an emerging theory termed the fetal basis of adult was recently expoused (Barner etal 2002). The theory states that several adult diseases have developmental origins. Interestingly relationships between early exposure to lead and neuropsychological abnormalities have been established during the course of life and chronic exposure to lead has been associated with the development of neurodegenerative diseases such as Alzheimer's, and Parkinson's disease (Winttel, 1995; Prince 1998). Schizophrenia has also been indicated as a plausible candidate, given that some of its premorbid features such as reduced attention, neurodegenerative impairment, and diminished educational attainment strongly resemble the behavioural deficits linked (Jones, 1993). These data suggest that developmental lead exposure can play a role in adult-onset neuropsychiatric or degenerative disorders. Indeed, adult neurogenesis has been proposed as a major factor to the understanding and even treatment of such conditions as Alzheimer's, depression and schizophrenia (Mitchell etal, 2004)

\section{Lead and Waste Sites}

In recent years, uncontrolled hazardous waste sites, some very close to schools, residences and commercial centres / areas e.g. shops etc) have been included in the list of sources of lead exposure. The United States Agency for Toxic substances and Disease Registry (ATSDR) reports that lead is released more at waste sites than other compounds (Walker, 2000). This implies that waste sites may constitute a neurotoxic risk

\section{Other Neurotoxicants in the Environment}

(i) Mercury: The health effects of mercury have been documented in Europe as early as the $16^{\text {th }}$ century. The expression "Mad as a hat" came into common use when hat makers were poisoned with mercury salts used to make colouring felt for fancy feathers. The hat makers were well known for their symptomatic shaking (tremor) muttering to themselves and stumbling. Methylmercury is the most wide spread source of toxic exposure to this liquid metal. Human epidemics of methyl $\mathrm{Hg}$ toxicity have occurred during the 1950s and 1960s in Japan. Striking epidemics of fatal and non fatal neurologic disease were caused by methyl mercury exposure from sea food in Minamata Bay and fresh water fish in Nigata. The neurologic syndrome being characterized by very many symptoms such as parastesia, slurred speech, muscle weakness and unsteady gait. Confusion hallucination and loss of consciousness were additional findings. Raised levels of methyl mercury found in hair and brains of the victims served as markers. These signs and symptoms may 
be observed in chemical exposure in our own environment albeit in subtle forms without relating them to chemicals exposure.

(ii) Solvents: These are of increasing significance in neurotoxicity. The use of solvents leads to the production and application of trillions of tons each year and results in multiple exposure episodes in occupational environments, home and in the community. The current use of solvents reflect expanded global economic growth including construction and reconstruction of many facilities .

Organic solvents comprise a large group of chemical liquids that are volatile and therefore are easily inhaled. One characteristic of organic solvents is that they are lipophilic; in liquid form they are readily absorbed by the skin.

Organic solvents are components of a variety of products such as paints, paint removers, and varnishes; adhesives, glues, dyes and print ink, floor and shoe polishes, creams, and waxes, agricultural products, pharmaceuticals and fuels. Some occupational solvents include methyl alcohol, acetone, methylene chloride and complex mixture of petroleum products.

Organic solvents are of particular concern because most of them are toxic in different ways and to different extent. The rise in the number of available organic solvents and the development of new ones utilizing them presents a significant public health challenge. All solvents are lipophilic and will at varying levels of exposure exhibit toxic effect on the CNS. The greater the solubility of the chemical in the brain membrane, the more potent and the longer the duration of its action (i.e. toxicity). Very little attentions seems to have been paid to organic solvents in this country despite their wide spread use in small and large scale industries.

(iii) Pesticides: The pesticides are another group that is very common and widely in application. Populations and individuals may have exposure to a range of pesticide concentrations, for instance in occupational exposure, passive exposure - bystanders exposure and exposure of the general public through food items containing pesticide residues (Anetor, Babalola, Lawanson, 2001).

Related to this are the varying additives to foods. In a typical year in the United States approximately 4.5 billion pounds of chemicals are used as pesticides. The exact quantity used in our country is not known but it is also estimated to run into several billions as well. This is not unexpected due to the attempt to increase food production for our increasing (teeming) population.

They are mainly used in agriculture to boost food and fibre. Some of the symptoms observed in a typical pesticide, organophosphate poisoning include ataxia, tremors, parastesia, slurred speech, loss of memory, insomnia, mental confusion and schizophrenic reaction. But these, as for the heavy metal mercury are often poorly recognized and related to chemical exposure. Anetor et al (2002) in a study of $\mathrm{Pb}$ workers have shown the neurochemical implications of biochemical changes that may improve assessment.

\section{Prognosis}

The nervous system as a target organ for toxicity has been the focus of much attention. The broad health, social, and economic significance of neurotoxicity is underscored by recent studies that have linked toxicants like lead with an increase in antisocial deliquent behaviour in adults (Needleman et al 1996; Needleman, 2004). It was reported recently that environmental pollution makes a big contribution to violent crime and antisocial behaviour, according to a provocative new analysis by an American political scientist. This scientist observed that toxic chemicals, in particular metals in water supplies and the environment can disrupt the neurological control mechanisms that normally inhibit human violent urges (Motluk, 1997).

Conventional theories link crime with social, economic and psychological factors but emerging data indicate that these factors cannot fully explain why some districts in the United States have only 100 violent crimes per 100,000 people each year 
while others have over 3000. Data on environmental pollution appear to account for a lot of the remaining variation. Investigators have analysed a wide range of statistics including crime figures from the FBI and information on industrial discharges of lead and other toxic chemicals both into water and into the atmosphere, compiled by the United States Environment a Protection Agency (EPA) (Motluk, 1997). Any association between environmental pollution in some of our industrial centers like Lagos, Port Harcourt and Warri, which incidentally are also hot spots for crimes? What of the ever present Niger Delta crises? Any relationship to environmental neurotoxicity?

The verdict after controlling for confounding variables by investigators is that environmental pollution has an independent effect on the rate of violent crimes, such as homicide, aggravated assault, sexual assault and robbery. These analyses have revealed that districts with the highest levels of environmental chemicals have crime rates three times the national average. The presence of pollution arising mainly from environmental chemicals has been described to be as big a factor as poverty. Though opinion is still divergent on this issue it definitely calls for closer attention to the problem of environmental pollution which holds poor prognosis for neurotoxicity.

\section{Micronutrients, Neurotoxicity And Biomarkers}

\section{a. Micronutrient and Neurotoxicity}

The notion that constituents of the diet can influence brain function is not novel. In the past few decades it has become clear that many constituents of the diet from macronutient to micronutrient influence brain function (Winick, 1976). The importance of nutrition and its effect on susceptibility to the development of diseases is becoming better understood, and poor nutritional status apparently can greatly influence chances of neurotixicity. Certain dietary deficiencies are known to increase the toxicity of a number pesticides and heavy metals such as lead and cadmium and other atmospheric contaminants
(Shakman, 1974, Mahaffey and Vandrerveen, 1979). This further exacerbates the prognosis of neurotoxicity in our sub region as these neuroprotective micronutrients are unfortunately on the decline as environmental chemicals are on the increase. (Anetor, Adeniyi and Taylor, 2002; Anetor et al, 2006).

Developing countries suffer from Micronutrient deficiency diseases (MDDs) . Many hypotheses have been put forward to explain the pathophysiology of cognitive impairment. Not withstanding that the brain possesses great structural and functional reserves and some physiological protective mechanisms, preservation of brain function with aging requires not only an adequate supply of energy, oxygen and essential nutrients but also directly and indirectly an adequate supply of micronutrients especially vitamins and minerals.

- Micronutrients, especially antioxidative vitamins and minerals such as vitamins $C$ and $E$ balance the redox status, counteract the deleterious effects of free radicals and protect the brain from damage from free radicals.

- There is also a significant correlation between riboflavin, niacin, folic acid and the vitamins; $\mathrm{A}$, $\mathrm{C}$, E, beta-carotene, $\mathrm{B}_{6}$ and $\mathrm{B}_{12}$ and cognitive capacities. Vitamin $\mathrm{C}$ and carotene plasma levels correlate with cognitive test results with specific function. (Duka and Stahelin, 2004). Anetor et al (2002) have reported a decrease in the potent general antioxidant vitamin $\mathrm{C}$ in lead workers and have proposed it as a component of a panel of biomarkers of neurotoxicity as indicated above.

Many environmental chemicals are known to generate free radicals which if unchecked could attack the nervous system rich in polyunsaturated fatty acids. Recently, the effects of neurotoxicants on lipid peroxidation has been investigated. Reactive oxygen species (ROS) were found to react directly with lipids resulting in the formation of free radicals and semistable peroxides. The harmful effects results from the reactivity of these free radicals with membranes and subcellular organelles. This thus provides a basis for the observations of Duka and Stahelin (2004) and Anetor etal (2002). Additional corroboration of the role of nutrients, especially micronutrients comes 
from the recent observation of Pabello and Bolivar (2005) on lead neurotoxicity. They observed that although there is no unifying mechanism on lead neurotoxicity, lead's ability to substitute for calcium and possibly zinc, is a factor common to many of its toxic actions. Thus careful manipulation of these nutrients could modulate $\mathrm{Pb}$ neurotoxicity.

We have also recently observed that reduced levels of thiamine and magnesium may potentiate the neurotoxicity of lead particularly in resource poor developing countries (Anetor et al, 2007)

\section{b. Biomarkers}

One of the principal aims of current clinical research is the identification of the speed, and accuracy of the diagnosis of certain diseases. Until recently, the most reliable procedure for assessing the neurotoxic effects of chemicals was the correlation of clinical observation and the result of histopathological examinations. Although exposure to some neurotoxicants may produce severe neurological dysfunction, it may not evoke a detectable tissue lesion. Non specific neuropathologic lesions result when a neurotoxicant produces severe vascular disturbance to the nervous system.

In contrast, specific lesions are produced when a neurotoxic agent interferes with particular structures and function of the neurons (AbouDonia et al, 1988). Thus biochemical markers are superior. There are a few biochemical methods that have been standardized for neurotoxicity testing. These may be classified into 3 groups

- biomarkers of exposure

- biomarkers of effect

- biomarkers of susceptibility.

More sensitive biomarkers appear desirable for risk assessment in the face of expanding volume of neurotoxic environmental chemicals.

\section{Molecular and Chemical Markers}

DNA may be used as an index for cellular proliferation and cell number in nervous tissues. An example of a biomarker of exposure. For example in the evaluation of the effect of lead during early development, there is a reduction in brain weight and a decrease in total brain protein without a change in the number of brain cells. (Krigman and Hosan, 1974). Early action of toxic agents may be manifested as a disturbance of the DNA repair enzyme system. This may be secondary to interference wit zinc level by for instance $\mathrm{Pb}$.

Chemicals may interact with the DNA molecule either by directly binding to the nucleic acid moiety or to its associated chromosomal proteins. Such changes in DNA molecules usually interfere with its functions, and these may be used for studying neurotoxicity.

RNA and proteins in nervous tissues may be changed as a result of exposure to neurotoxic chemicals. A simple procedure to study RNA and protein synthesis is the use of radiolabelled precursors and following the rate of incoporation into macromolecules in vitro or in vivo (Dunn, 1975). For instance, mercury inhibits amino acid transport across the BB barrier (Patridge, 1976); similar results were obtained with lead (Lovenzo and Gerwitz, 1977).

Many neurotoxic agents have been shown to alter the turn around rate and consequently the metabolic half life of the neurotransmitters (Costa, 1970). Changes in brain catecholamine concentrations have been implicated in the neurotoxocity of carbondisulphide as it increased dopamine and decreased norepinephine concentrations by inhibiting dopamine $\beta$ hydroxylase (Mckenna and Destefano, 1975).

Organophosphorus compound insecticides exert their acute effect by inhibition of

acetylchrolinesterase that leads to accumulation of acetylchroline at receptors in both the central and peripheral nervous systems (Abou-Donia 1985). Lead (Silbergeld and Goldberg, 1975), the chlorinated hydrocarbons, chlordecone and several others have all been shown to interfere with neurotransmitter uptake process. Thus their evaluation may serve as biomarkers of neurotoxicity.

A simple common place biomarker of neurotoxicity of both susceptibility and effect is calcium. Influx of $\mathrm{Ca}^{++}$upon depolarization of the nerve endings triggers the release of neurotransmitters from synaptic endings (Cotman et al, 1976). Lead (Bondy et al, 1979) and 
manganese (Kirpekar et al, 1970) have all been reported to interfere with calcium-dependent neurotransmitter release. Ion channels regulate many neuronal function. Thus perturbation of these channels may be reflected by variation in ion levels. A well known one is $\mathrm{K}^{+}$. The $\mathrm{Na}^{+} / \mathrm{K}^{+}$ ATPase pump is required for maintaining $\mathrm{Na}^{+} / \mathrm{K}^{+}$ concentrations. The pump may be inhibited by some toxicants such as tetrodotoxin and saxitoxin. (This is the mechanism of toxicity of the peptide toxin, scorpion toxin (Catterall, 1977) which has recently been shown to have $\mathrm{K}^{+}$channel affinity.

It is clear that biochemical tests now called markers can play a major role in detecting, predicting and screening for neurotoxicity. This is a challenge to all medical scientists who should develop panels as markers of neurotoxicity that do not necessarily have to be sophisticated and thus routinely applicable.

Anetor, et al (2002) have proposed a simple panel as biomarker of lead induced neurotoxicity in lead workers. This panel comprises of Blood lead level, Plasma $\mathrm{K}^{+}$, Serum total $\mathrm{Ca}^{2+}$, Ionised $\mathrm{Ca}^{2+}$, Serum cholinesterase and Ascorbc acid status.

It must be mentioned that caution must be exercised in analyzing and evaluating the results of studies which relate biochemical correlates to neurotoxicity.

\section{Clinical Evaluation for Neurotoxicity}

It is perhaps appropriate to briefly outline clinical evaluation of neurotoxic states. The clinical evaluation of neurotoxicity consists of the under listed:

Study of the patient's history:

- including disease of the nervous system

- chronic health problems

- drug use

- exposure to industrial or environmental chemicals

- assessment of the patient's sensory, motor, reflex and cranial nerve function by simple non invasive tests.

- Inspection of the patient's work environment including:

Monitoring for the possibly offending neurotoxic chemicals

\section{Clinical Symptoms Suggestive of Central Nervous System Disturbance}

The following non-specific symptoms may be suggestive of central nervous system disturbance

- $\quad$ Dizziness

- Vertigo

-Headache

-Swinging mood

-Fatigue

-Memory loss

- Miscellaneous cognitive disturbances

These are non-specific clinical symptoms that can be confused with other common pathologies.

\section{Effects of Chemicals on the Peripheral Nervous System (PNS)}

The PNS is one of the primary targets of many environmental chemicals. Effects of chemicals on this system may manifest as indicated below:

- changes in breathing rate

- changes in heart rate

- changes in tendon reflex

- changes in perspiration

- changes in gastrointestinal function

With this background it is possible to anticipate neurotoxicity in exposed individuals and take measures to prevent or mitigate neurotoxicity and carry out further investigations to arrive at a definitive diagnosis and subsequent monitoring.

\section{Conclusion}

It is important to emphasis that evidence abounds that exposure to chemicals which are in increasing use in industry, agriculture and in consumer products can induce neurotoxicity. The number of individuals with neurotoxic disorders and the extent of neurologic disease and dysfunction is uncertain. However, it is known that a large number of people are exposed to environmental chemicals that in sufficient doses can pose a neurotoxic risk. This is even more so in this subregion owing to the decline in the availability of micronutrients which are known to be neuroprotective. Thus the prognosis may be poorer. The response of a population to over exposure to neurotoxicants may have broad health, 
social and economic implications. This has been aptly described as follows by Kilburn (1997).

"Imagine a plague so generalized, so devastating, yet so insidious that a majority of human kind becomes dysfunctional, suppose further that this dysfunction affects the brain so that perception and memory gradually fade, disorganizing behaviour and thrusting its victim into a world of diminishing prospects and individual (social) disorganization. Should such individual dysfunction rise above a trivial frequency the collective cost to society could be enormous". Health education at the individual and population levels is thus highly desirable

Undoubtedly, the magnitude and potential severity of neurobehavioural toxicity problems make it imperative to invest in facilities required to strengthen the basis for preventive intervention, the forerunner of which is the development of biomarkers for detecting, predicting and screening for neurotoxicity both at the individual and population levels. The human health consequences of increased reliance on chemicals, petrochemicals and pharmaceuticals calls for the more pragmatic precautionary principle rather than weight of evidence so that we may not be victims of late lessons from early warnings which biomarkers seek to prevent.

\section{ACKNOWLEDGEMENT}

We wish to acknowledge the encouragement of late Professor L.S. Salimonu, FAS, who was the Chairman at the Biomedical Science Week at which the Framework of this review was given as a guest lecture and for suggesting its publication

\section{REFERENCES}

Abou-Donia, M.B., Lapadula, D.M., Carrington, C.D. (1988). Biochemical Methods for assessment of neurotoxicity. In: Perspectives in Basic and Applied Toxicology, Ballantyne, B. editor, Butterworth and Co. Ltd London pp. 1-30.

Adeniyi, F.A.A., Anetor, J.I. (1999). Lead poisoning in two distant states of Nigeria: an indication of the real size of the problem. Afr. J. Med. Med. Sci.; 28: 107-112.

Anetor, J.I. (2001). High blood lead levels in the general Nigerian population: Causes and implications.
The World Bank Clear Air Initiative in Sub-Saharan Africa. National Conference on the phase-out of leaded Gasoline in Nigeria. Working paper Number 6. The World Bank, Washington DC 204 33, USA pp. 27-37.

Anetor, J.I., Adeniyi, F.A.A. (2000). Lead poisoning in Africa: a silent epidemic Afr. Sci.; 1: 249-256.

Anetor, J.I., Adeniyi, FAA and Taylor G.O.L. (2002). Neurotoxic implications of some biochemical changes in lead workers. Afr. J. Med. \& Pharm. Sci 6: 33-39.

Anetor, J.I., Babalola, O.O., Anetor, G.O. (2006). Antioxidant micronutrient as an intersectoral link between health and agricuture Afr. J. Biomed Res. 9: 1-10.

Anetor, J.I., Babalola, O.O., Lawanson R.F. (2001). Assessment of the risk of organophosphate poisoning in male Nigerian agricultural workers. Nig. J. Environ Res. Mgt.; 1: 84-88.

Anetor, J.I., Ajose, A.O., Adebiyi, J.A., Akingbola, J.S., Iyanda, A.A., Ebesunu, M.O., Babalola, O.O., Adeniyi, F.A.A. (2007). Decrease thiamine and magnesium levels in the potentiation of the neurotoxicity of lead in occupational lead exposure. Biol. Trace Elem. Res. 116: 43-51.

Barker et al. (2002). Fetal origins of adult disease: Strength of effects and biological basis Int. J. Epidemiology. 31 (6) 1235-1239.

Bondy, S.C., Harrington, M.L., Anderson, C.L. et al. (1979). Low concentration of an organic lead compound alters transport and release of putative neurotransmitters. Toxicol. Lett. 3, 35-41.

Bonilla E. (1980) L - tyrosine hydroxylase activity in the rat after chronic oral administration of manganese chloride. Neurobehav. Toxicoliteratol. 2, $37-41$

Brell, R.J., McCauley, P.T., Taylor, U.N., Kroflen, K.M. (1983). The effects of Lead on a developing nervous system in the rat. Neurotoxicology; 4: 1-8

Carlsen, E., Giwercman, N., Meiding, N., Shakeback, H.E. (1992). Evidence for decreased quality of Semen during the past 50 years. BMJ; 305: 332-337.

Carpenter, D.O., Arcaro K, Spink, D.C. (2002). Understanding the human health effects of chemical mixtures. Environ. Health perspect; 110: 25-42.

Castleman B. Global coporate policies and international “double standards” in occupational and environmental. Research Int. J. Occup Environ Health 5: 6164.

Congress of the United States (1990) Neurotoxzicity. Office of Technology Assessment, Washington, DC.

Duka L, Stahelin HB (2004). Nutrition and cognitive impairment: the role of micronutrients. Alzheimer Insights: An International Education Newlett. 2004, 6: 
1-4

IPCS: (International Programme on Chemical

Safety (1992). Cadmium. Environmental Health Criteria 134. Geneva: World Health Organization.

Williams, P.L., James, R.C., Roberts, S.M. (2000). Principles of Toxicology. Environmental and Industrial applications. John Wiley and Son, Inc. New York. 2000 Pp 145-155.

Johnson J. (1997) Better Chemical testing urged Chemical and Engineering News 33: 27-28.

Jones, B. (1993) Schizophrenia: Into the next millennium. Ca. J. Psychiatry 38 (Suppl. 3) 567-569

Kilburn, K.H. (1997). Introduction: the brain's new chemical plagues. In Kilburn, K.H., editor Chemical Brain Injury. New York: Van Nostrand p.1.

Kobayashi, H, Suzuki,T., Sato, I., Matrusatu, N. (1994). Neurotoxicological aspects of organotin and Lead Compounds on Cellular and Molecular Mechanisms. TEN; 1: 23-31.

Kreisel, W. (1998) Environmental Health at the dawn of the Twenty-first century: Opportunities and challenges. WHO Environ. Health Newwslett. 140, 28 pp. 26-28.

Mahaffey, K.R., Vanderveen, J.E. (1979). Nutrient toxicant interaction: Susceptible populations. Environ Health Perspect; 29: 81.

Mitchell, B.D. etal (2004). Constitutive and induced neurogenesis in the adult mammalian brain: Manipulation of endogenous precursors towards CNS repair. Dev. Neurosci. 26 (2-4) 101-117

Motluk, A. (1997). Pollution may lead to a life of crime New Scientist. 54: 4

Needleman, H. (2004). Lead poisoning Ann. Rev. Med. 55, 209-222.

Needleman, H.L., Gummol, C.E. Leviton, A. et al (1979). Deficit in psychologic classroom performance of children with elevated lead levels. N. Eng J. Med., 300, 689 - 95.

Needleman, H.L., Reiss, J.A., Tobin, M.J. et al. (1996). Bone Lead level and delinquent behaviour. JAMA, 275: 363-9.

Nriagu J.O. (1992). Toxic metal Pollution in Africa. Sci. Total Environ. ; 121: 1-37.

Nriagu, J.O., Blankson, M.C., Ocran, K. (1996). Childhood lead poisoning in Africa: a growing public health problem: Sci. Total Environ. 181: 93-100,

Okoye C.O.B. (1994). Lead and other metals in dried fish from Nigerian markets. Bull. Environ. Contam. Toxicol. 52: 825-832.
Pabello, N.G., Bolivar, V.J. (2005). Young brains on lead: adult neurological Consequences. Toxicol. Sci. 86: 211-213.

Poarco N, Matos E, Vainio H, Bolletha P, Kogevinas M, (1994) (eds). Occupational Cancer in developing countires IARC Sci. Publ 129.

Prince, M. (1998). Is chronic low-level lead exposure in early life an etiologic factor in Alzheimer's disease? Epidemiology 9 (6), 618-621.

Ryan, D., Levy, B., Pollack, S., Walker, B. (1999). Protecting children from lead poisoning and building healthy communities. Am. J. Public Health, 89: 83334.

Shakman, R.A. (1974). Nutritional influences on the toxicity of environmental pollutants. Arch. Environ. Health; 28: 105-113.

Shellenberger, M.K. (1984) Effect of early lead exposure on neurotransmitter systems in the brain. A review with commentary. Neurotoxicology, 5: 177212.

Silbergeld, E.K. (1992). Mechanism of lead toxicity, or looking beyong the Lamppost. FASEB J., 320: 1-6. Szpin. New thinking on neurodevelopment Environ. Health Perspect. (2006); 14: A101-A107.

Thomas V.M., Socolow, R.H., Fanelli, J.J., Spiro, T.G. (1999). Effects of reducing lead in gasoline: an analysis of the International experience. Environ. Sci. Tech.; 33: 3942-8

Tomatis L., Huff J (2001). Evolution of cancer and primary prevention. Environ Health Perspect 109: A458-A460 (editorial)

Tsubaki I, Trukayamak (1977): Minamata Disease. Tokyo, Kodansha; Amsterdam Elsevier.

US EPA (United States Environmental Protection Agency) (1990) Toxic Release Inventory Environmental Protection Agency, Washington, DC.

Verity, M.A., Goyer, R.A, Klassen, C.D., Walker, M.P. (editors) (1996). The nervous system in metal toxicity, Academic Press, San Diego pp. 199-226.

Walker, B. (2000) Neurotoxicity.in human beings. J. Lab. Clin. Med. 136: 168-180.

Winick, M. (1976). Malnutrition and brain development. Oxford University Press, New York .

Winttel, R., Kuhn, W. and Pruntek, H. (1995). Chronic intoxication with lead and sulphur compounds may produce Parkinson disease. J. Neurae Transm. Suppl. 46, 183-187. 